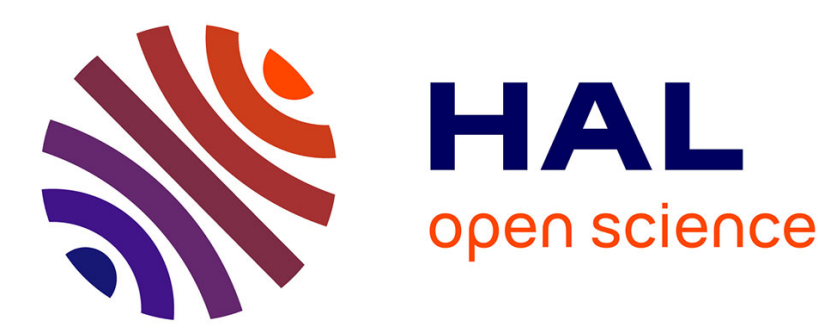

\title{
Impact Sound Insulation: The Standard Tapping Machine Shall Learn to Walk! \\ W Scholl
}

\section{To cite this version:}

W Scholl. Impact Sound Insulation: The Standard Tapping Machine Shall Learn to Walk!. Building Acoustics, 2001, 8, pp.245 - 256. 10.1260/1351010011501830 . hal-01509348

\section{HAL Id: hal-01509348 \\ https://hal.science/hal-01509348}

Submitted on 17 Apr 2017

HAL is a multi-disciplinary open access archive for the deposit and dissemination of scientific research documents, whether they are published or not. The documents may come from teaching and research institutions in France or abroad, or from public or private research centers.
L'archive ouverte pluridisciplinaire HAL, est destinée au dépôt et à la diffusion de documents scientifiques de niveau recherche, publiés ou non, émanant des établissements d'enseignement et de recherche français ou étrangers, des laboratoires publics ou privés. 


\title{
Impact Sound Insulation: The Standard Tapping Machine Shall Learn to Walk!
}

\author{
W. Scholl \\ Physikalisch-Technische Bundesanstalt, Braunschweig und Berlin, \\ Bundesallee 100, 38116 Braunschweig
}

\author{
This paper is dedicated to Prof. W. Fasold, head of the Room Acoustics Department \\ of the Fraunhofer-Institut für Bauphysik from 1992. \\ He celebrates his 70th birthday in August 2001.
}

\begin{abstract}
Previous research on the standard tapping machine has shown that the impact on a floor depends strongly on the combined system of floor and tapping hammers. This means that in general, a particular measure to reduce the impact sound pressure level can be advantageous with one impact source and disadvantageous with another. Conversion from one impact source to another has to be made for each floor individually, provided there is a sufficient knowledge of the dynamic properties of the source and floor. So, if the standard tapping machine is to be used to characterise a floor with respect to walking noise, the only simple way out of the problem is to make it 'behave like a walker'. That means it should have the same source impedance. Investigations at the Fraunhofer-Institut für Bauphysik Stuttgart showed that this could be achieved by small modifications to the standard tapping machine. Comparisons using a concrete floor and a wooden joist floor have proved that results using such a modified tapping machine are much closer to walking noise than the results using the standard tapping machine.
\end{abstract}

\section{INTRODUCTION}

This article is the continuation of a former publication about "Impact sound insulation of timber floors: interaction between source, floor coverings and load bearing floor" [1]. For measurements of the impact noise level of floors according to ISO 140-6 [2], a standard tapping machine is used as an impact sound source, which drops $500 \mathrm{~g}$ steel hammers onto the floor ten times per second. The noise level thus produced in the room below the floor is believed to be representative of the noise produced by 'real life' sources such as people walking or jumping on the floor. When a walker is replaced by a tapping machine it is assumed that the classification of the acoustical performance of different floors is unchanged, and that the difference of impact input by the sources is a constant typical of those sources, but independent of the floor under test. Thus the noise of the standard hammer machine could be easily converted into walking noise just by 
adding a known correction to the measured (hammer) impact sound pressure levels.

However, this approach does not work. The reason is that both the impact source and the receiving structure have a mechanical impedance, and the actual exciting force acting on a structure depends on the ratio of the impedances of the source and structure, as well as the 'strength' of the source. There may be some limited areas, where there is an approximate simple relation between hammer and walking noise, that is when the floor structure can be represented as a linear system with a much greater impedance than the source. In general this condition is not fulfilled, which becomes obvious when trying to apply results from heavy and hard floors to lightweight or soft ones (cf. figure 14 in [1]). Two solutions of the problem were proposed in [1]:

1 to characterise the dynamic system of impact source and floor by its dynamic properties, such as impedances and transfer functions (radiated sound power to input force, e.g.) or

2 to define a typical impact sound source - for example jumping children or adults in high-heels - and to imitate it by a mechanical source, which is as simple as possible.

Experiments using the second approach are reported here.

\section{DEVELOPMENT OF A WALKER LIKE TAPPING MACHINE}

The aim of the investigation was to construct a simple mechanical impact source with a mechanical impedance as close as possible to that of a walker. At the same time this source should resemble the ISO standard tapping machine to retain the ISO measurement method [2] and to make it easier for people to get accustomed to a new source. Firstly, measurements of the impedance of two people, at their heels, were made. Secondly, the frequency spectrum of the impedance was reconstructed by a combination of springs and masses. Such a simplified walker system was then applied on two mechanically very different floors - a heavy concrete floor and a timber joist floor - and the results compared with those using the ISO standard tapping machine, and a real walker to produce impact sound levels.

\subsection{Impedance measurements of walkers}

The input impedance of two adult males was measured by exciting their heels with an electrodynamic shaker (Figure 1). The moving shaft of the shaker was fixed to an accelerometer, a force transducer and a $45 \mathrm{~mm}$ diameter aluminium plate, to spread the input force on the heel. The walkers were tested with and without shoes and in sitting and standing positions. Figures 2 and 3 show the resulting impedance level spectra for each of the two people, which is defined as

$$
L \quad=20 \cdot \lg \left(\frac{F / F_{0}}{v / \mathcal{V}_{0}}\right) \quad d B
$$

where $\mathrm{F}$ is the force at, and $\mathrm{v}$ the velocity of the force transducer/aluminium plate interface, both are RMS values. The reference values were chosen such that $0 \mathrm{~dB}$ correspond to $100 \mathrm{Ns} / \mathrm{m}$. The results show approximately a negative slope at low and 


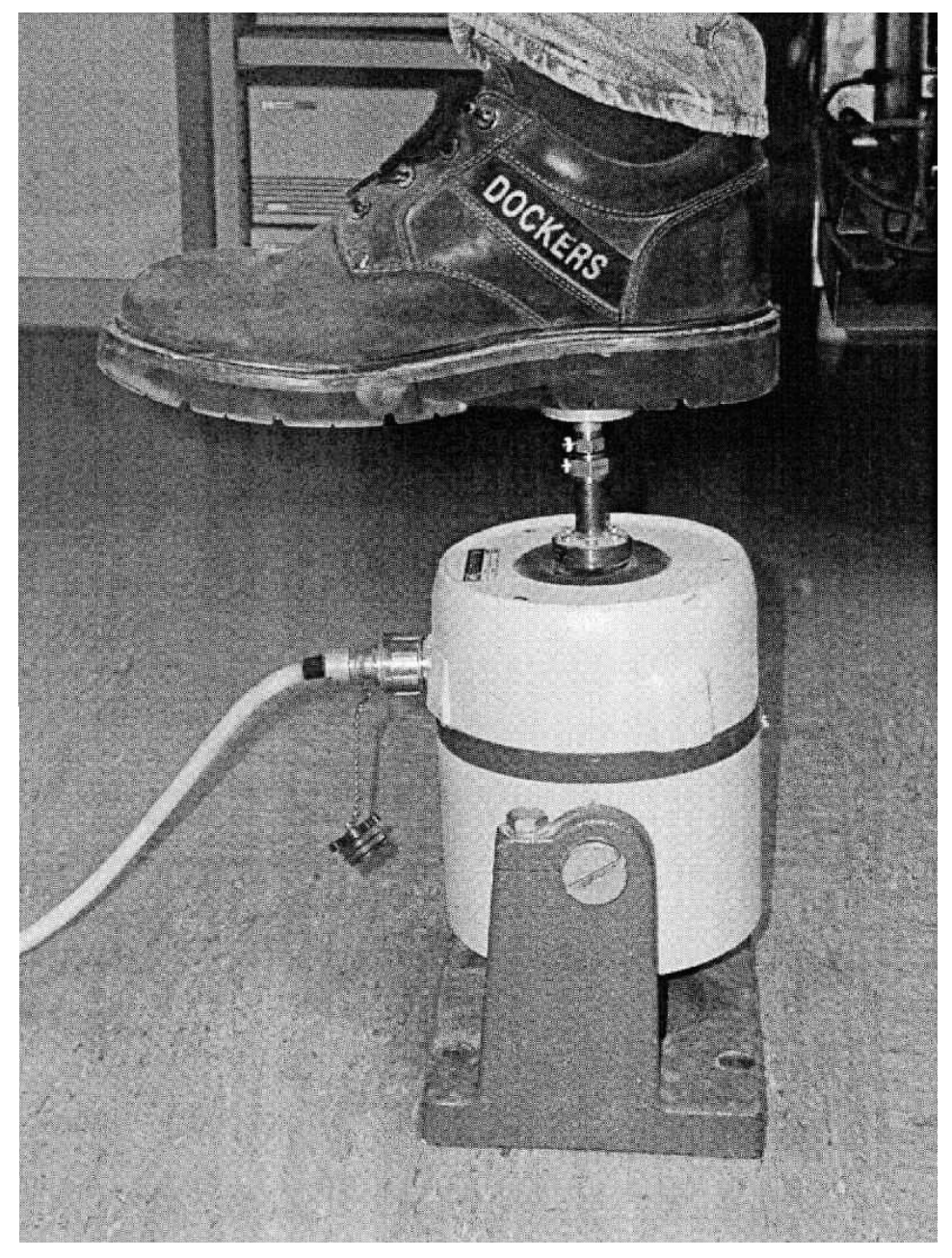

\section{Figure 1}

Instrumentation to measure the mechanical source impedance of a walker. From the bottom: electrodynamical shaker, acceleration transducer, force transducer, aluminium disc (45 $\mathrm{mm}$ diameter), foot with shoe

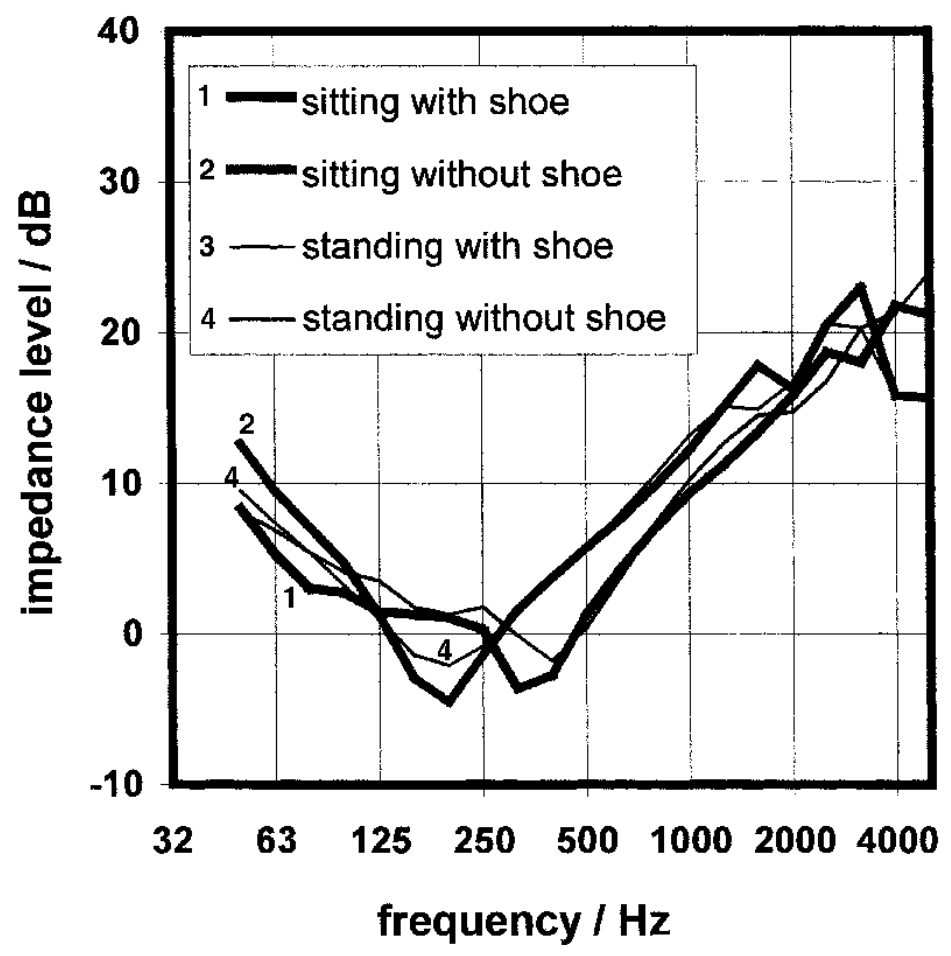

Figure 2 Measured impedance level spectra for the first of the two people (JK), who were tested with and without shoes and in sitting and standing positions $(0 \mathrm{~dB}=100 \mathrm{Ns} / \mathrm{m})$ 
a positive slope at high frequencies with the minimum in between shifted to higher frequencies when shoes are worn. Interestingly, the differences between the standing and sitting positions are rather small, indicating that only the lower part of the leg may be involved dynamically. When repeating the measurement with shoes, shown in Figure 2, the level differences in the third octave bands were about $2 \mathrm{~dB}$ or less.

\subsection{Approximation of the walker impedance by a simple mechanical system}

The requirement is shown in Figure 4. The source impedance of the walker is to be replaced by a spring-mass combination, which yields the same impedance when looking into the system from below. The bare-footed walker of Figure 2 was taken as a basis. Shoes were left off to prevent additional unknown influences and because this was considered to be the more critical case with regard to low frequency excitation. The negative and positive slopes in Figure 2 display mass/spring characteristics. From this the mass-spring-mass system shown in Figure 5 was derived. Also shown is its calculated impedance level spectrum. As indicated, different approximations are possible which have not been investigated in detail. The spring needs a high loss factor of 0.8 , to give a broad enough minimum. It should be noted, that the small mass at the bottom includes a portion of $25 \mathrm{~g}$ belonging to the aluminium plate and part of the force transducer. The mass on top represents the dynamically resting part of the human body. It can be reduced to $500 \mathrm{~g}$ with only a small error at low frequencies, because it is dynamically decoupled from the input by the spring. The decoupling starts somewhere

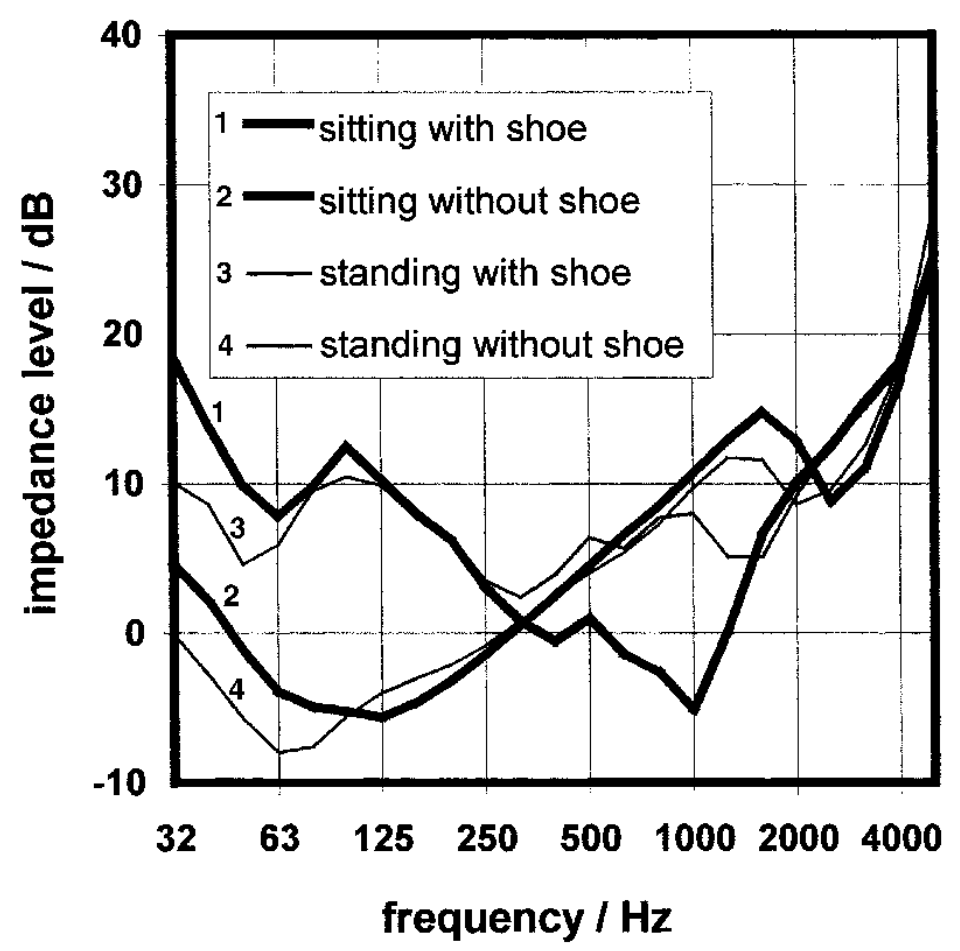

Figure 3 Measured impedance level spectra for the second of the two people (AJ), who were tested with and without shoes and in sitting and standing positions $(0 \mathrm{~dB}=100 \mathrm{Ns} / \mathrm{m})$ 


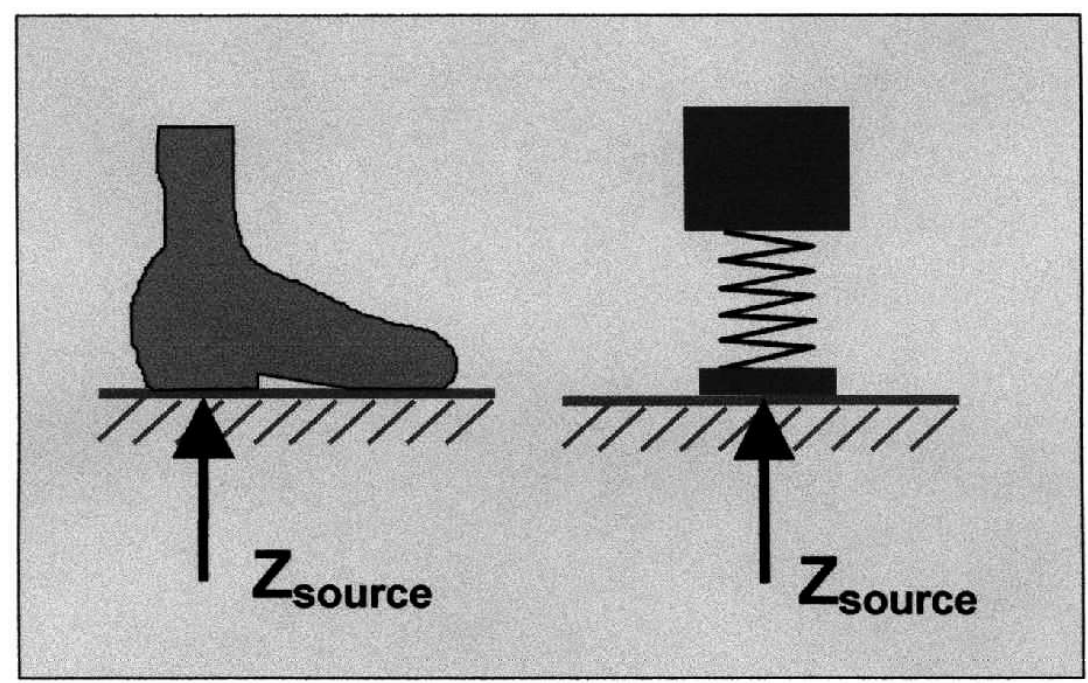

Figure 4 Approximation of the walker's source impedance by a mechanical model
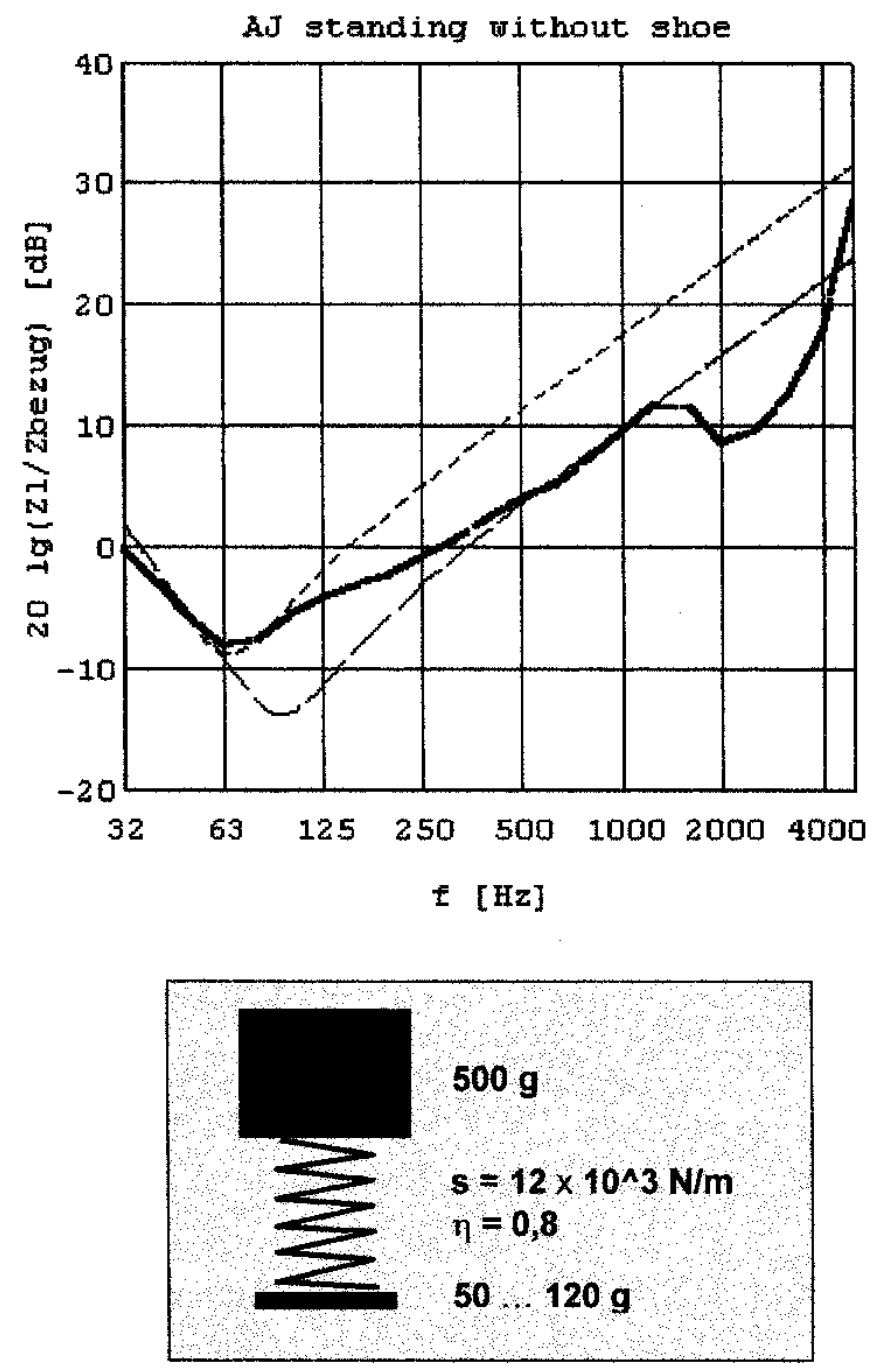

Figure 5 Chosen mass-spring-mass system to simulate the walker. Thick line: measured impedance level of the walker referred to in Figure 2. Thin lines: lower mass $=50$ and $120 \mathrm{~g} ; \mathrm{s}=$ stiffness; $\eta=$ loss factor, Reference impedance (Zbezig) $=100 \mathrm{Ns} / \mathrm{m}$ 
between 25 and $60 \mathrm{~Hz}$ depending on the load on the floor tested. Using a mass of 500 g means that the ISO 140 standard tapping machine can obviously be retained, with only minor modification.

For the experiments described below the spring was changed to a stiffness $\mathrm{s}$ of $24 \times 10^{3} \mathrm{~N} / \mathrm{m}$ and a loss factor $\eta=0.2$ simply because a material with these characteristics was available. Because it was intended to carry out impact sound level tests on hard floor surfaces the small lower mass could be omitted as it merges with the much larger mass of the floor during the contact time, even when the floor it is a 'lightweight' timber floor. Omitting the small lower mass is not allowed of course, when exciting softly covered floors, or when the mass of the excited structure within half a bending wavelength is not large compared to the omitted mass. Finally the springs do not have to be fixed to the falling source masses but can be realised by a soft layer laid on the bottom. Such an arrangement is shown in Figure 6. It consists of a standard tapping machine acting upon five layers of a rubber cork mixture fixed with adhesive tape. The falling height can (but does not necessarily have to) be adjusted to the thickness of the soft layers. As the movement of the spherically shaped hammer heads of the tapping machine are controlled by the soft material, the contact stiffness between hammer and floor does not depend on the special floor under test and thus one artificial and misleading effect of the standard tapping machine is eliminated.

The possibility of using rubber heads instead of (at that time) brass heads for the tapping machine was discussed by Gerretsen in 1976 [3], who presumed that the force applied to different floors could more closely resemble that of footsteps. Gerretsen

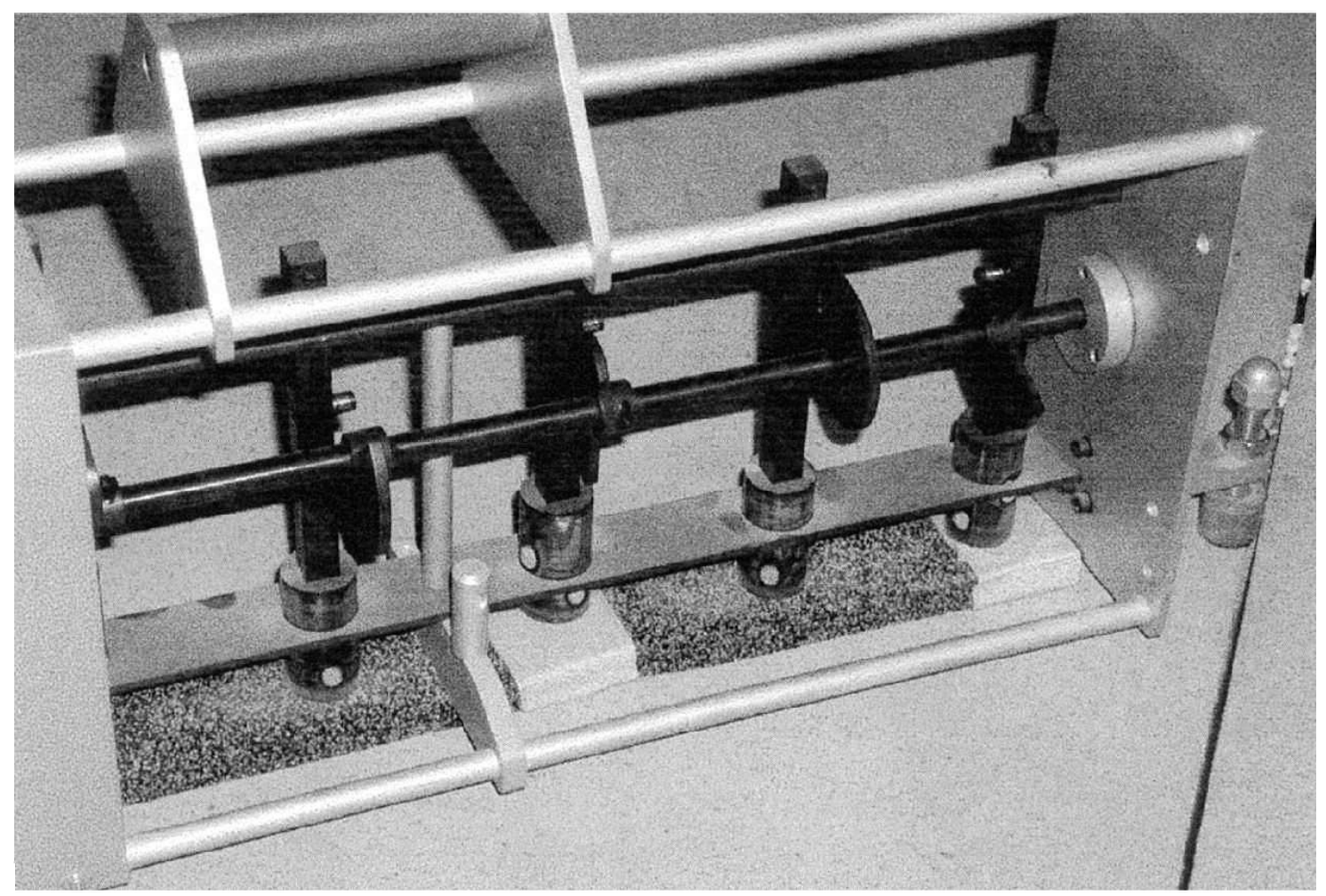

Figure 6 The modified tapping machine, with the hammers acting upon five layers of a rubber cork mixture, fixed with adhesive tape 

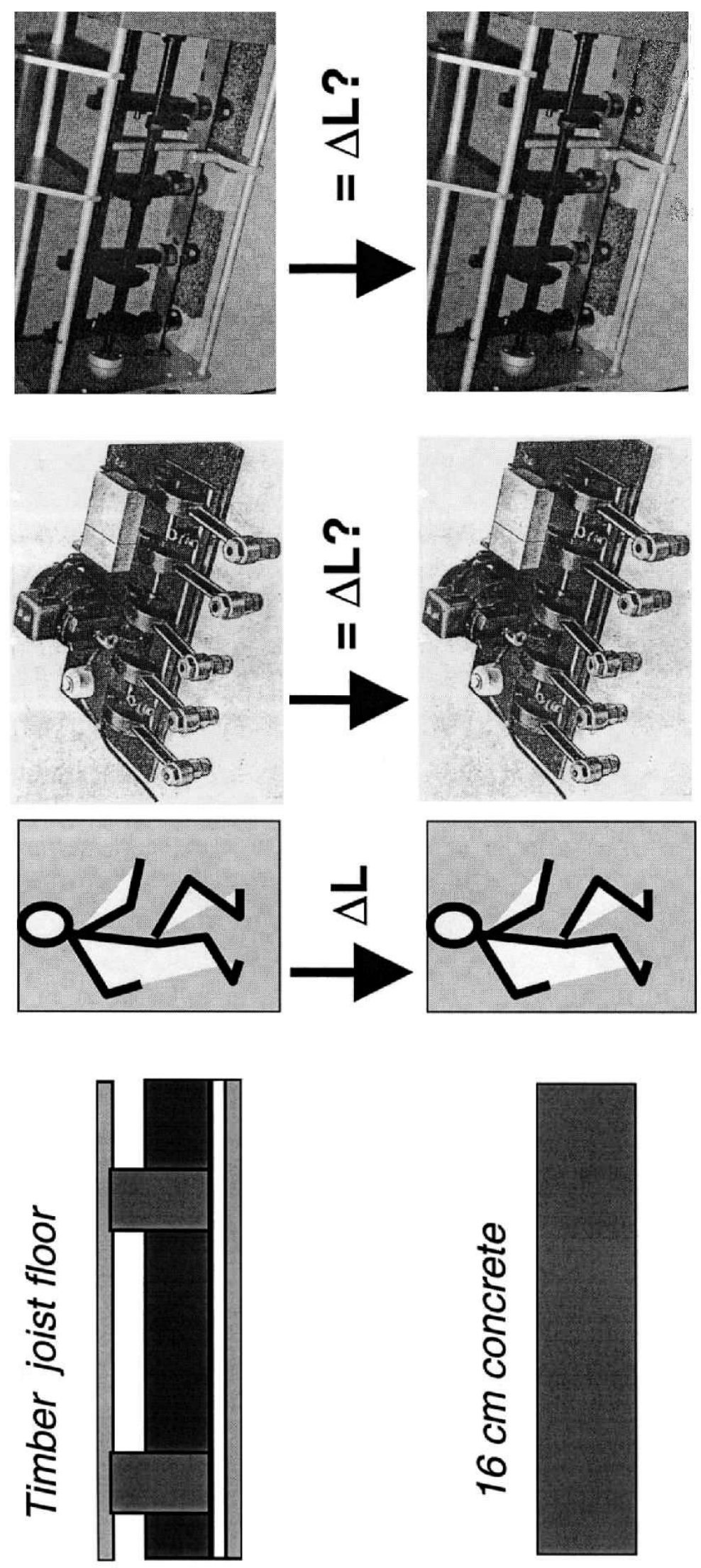

Figure 7 The two different floors types tested: a bare concrete floor $(160 \mathrm{~mm}$ thick) and a timber joist bare floor (22 mm chipboard, 120 by $180 \mathrm{~mm}$ timber joists with $100 \mathrm{~mm}$ mineral wool in between, $24 \mathrm{~mm}$ laths and $12.5 \mathrm{~mm}$ gypsum board). Impact sources: walker, the modified and standard tapping machines. $\Delta \mathrm{L}=$ difference of the normalised impact sound pressure levels produced by the respective source. 
presented the tapping machine noise level difference between brass and rubber heads as an average for 25 floor constructions, as different as bare floors, carpeted floors, wooden top floors and floating floors. The spread of the differences $( \pm 2.6 \mathrm{~dB}$ at $63 \mathrm{~Hz}$ to $\pm 12.9 \mathrm{~dB}$ at $2000 \mathrm{~Hz}$ for $90 \%$ confidence limits) seems to confirm the strong influence of the floor construction on the source input.

\section{IMPACT SOUND LEVEL MEASUREMENTS WITH THE MODIFIED TAPPING MACHINE}

A tapping machine, modified as mentioned above, was used for impact sound pressure level measurements according to ISO 140-6. Two different floors types were tested:

- a $160 \mathrm{~mm}$ thick concrete bare floor and

- a timber joist bare floor with $22 \mathrm{~mm}$ chipboard on top, 120 by $180 \mathrm{~mm}$ timber joists, $100 \mathrm{~mm}$ mineral wool in between, $24 \mathrm{~mm}$ laths and $12.5 \mathrm{~mm}$ gypsum board below.

The purpose of the tests was to determine whether the modified tapping machine would yield the same normalised impact sound level difference between the two floors as would a walking person, and to compare the results with those of an unmodified

$180 \mathrm{~mm}$ concrete floor

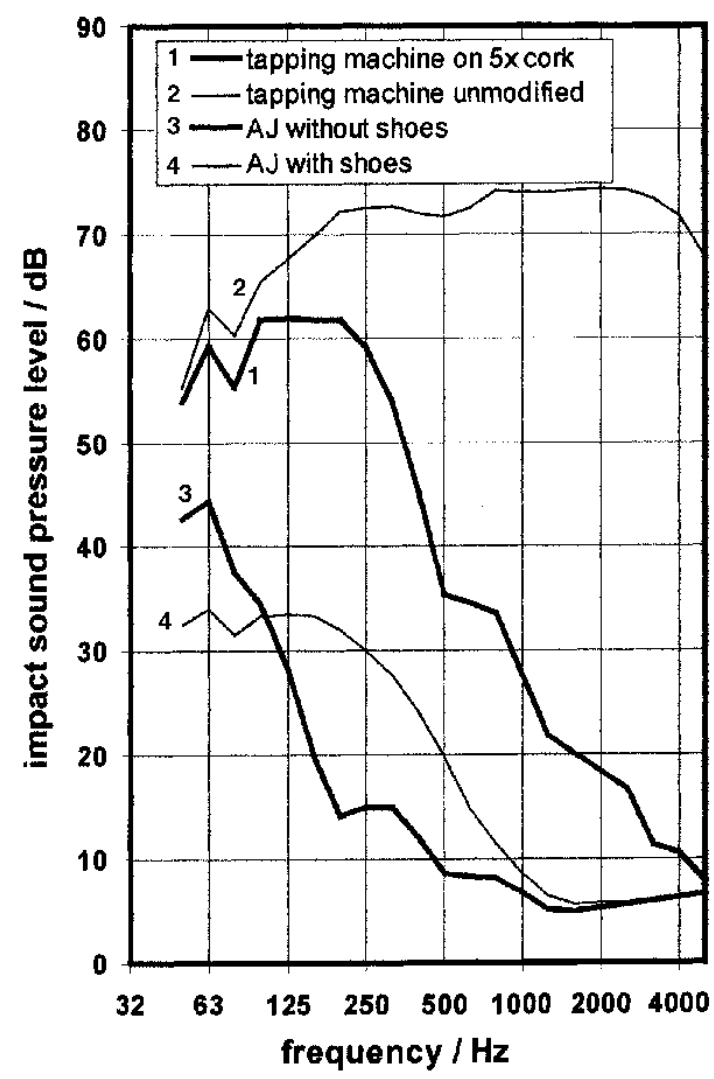

timber joist floor

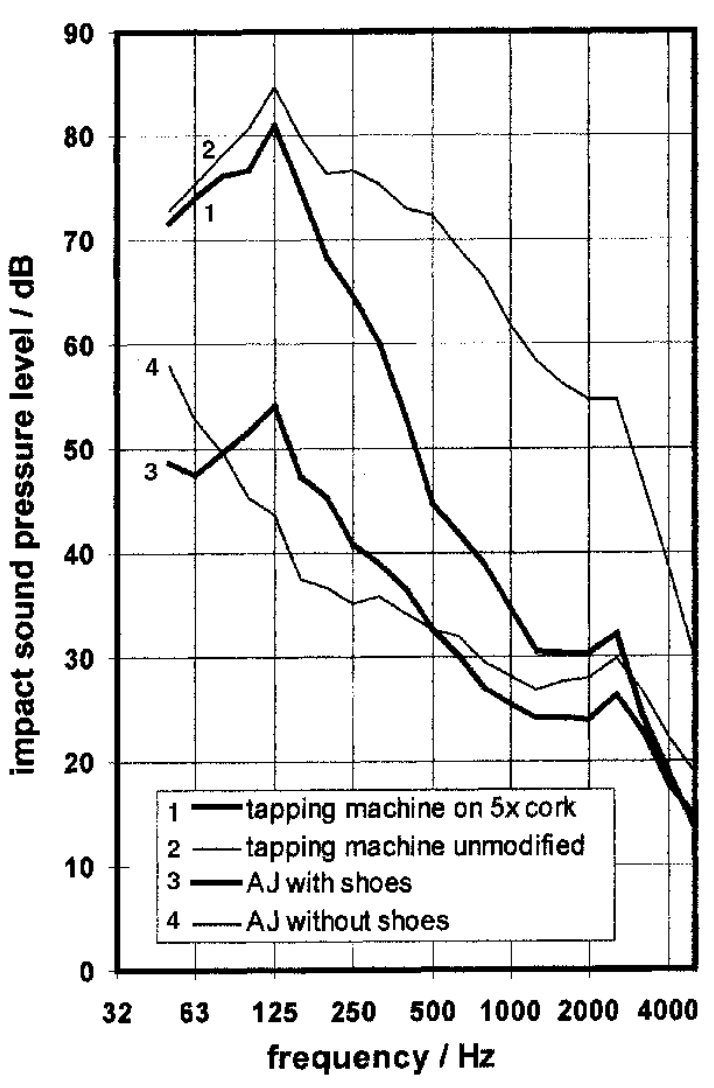

Figure 8 Impact sound pressure level frequency spectra, using the modified and standard tapping machines, and a walker with and without shoes 
standard tapping machine (Figure 7). The absolute values of the impact sound pressure levels should not be compared directly, because the three sources are of different strength.

The resulting frequency spectra of the impact sound pressure level are presented in Figure 8 . The most obvious effect of the tapping machine modification is the reduction of the higher frequency input, which makes the impact sound pressure level spectrum look more like a walker's spectrum than that of the standard tapping machine, especially on the hard surface of the concrete floor. A comparison of the corresponding single number values, the weighted impact sound pressure level $\mathrm{L}_{\mathrm{n}, \mathrm{w}}$ and the Aweighted sound pressure level $L_{A}$, is shown in Figures 9 and 10 . Regarding $L_{n, w}$, the

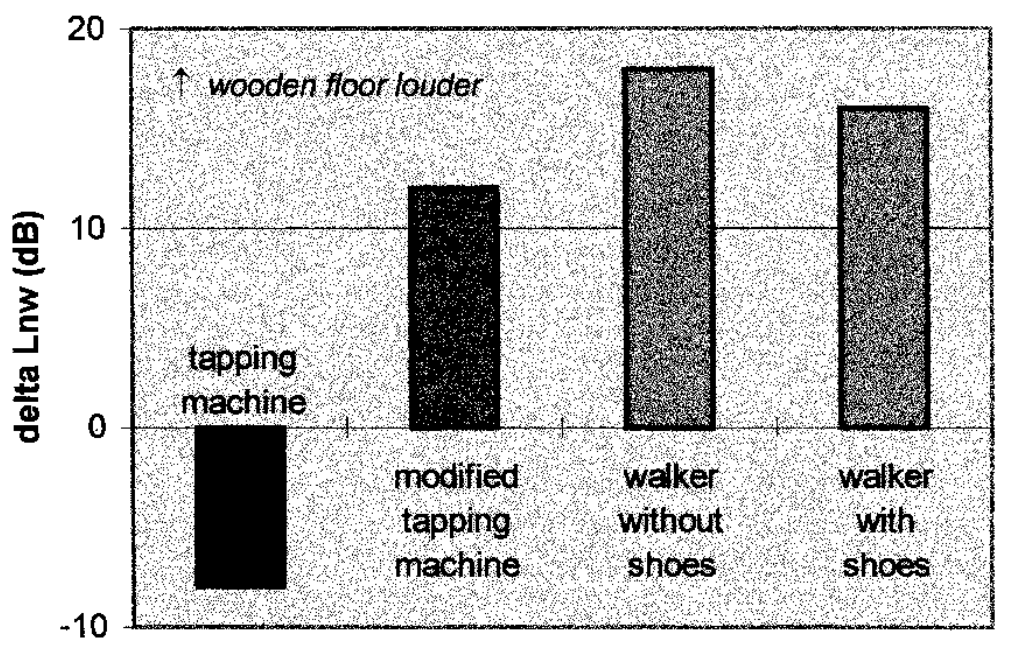

Figure 9 Difference of the weighted impact sound pressure level $\mathrm{L}_{\mathrm{n}, \mathrm{w}}$ for the wooden and concrete floors, using the modified and standard tapping machines, and a walker with and without shoes

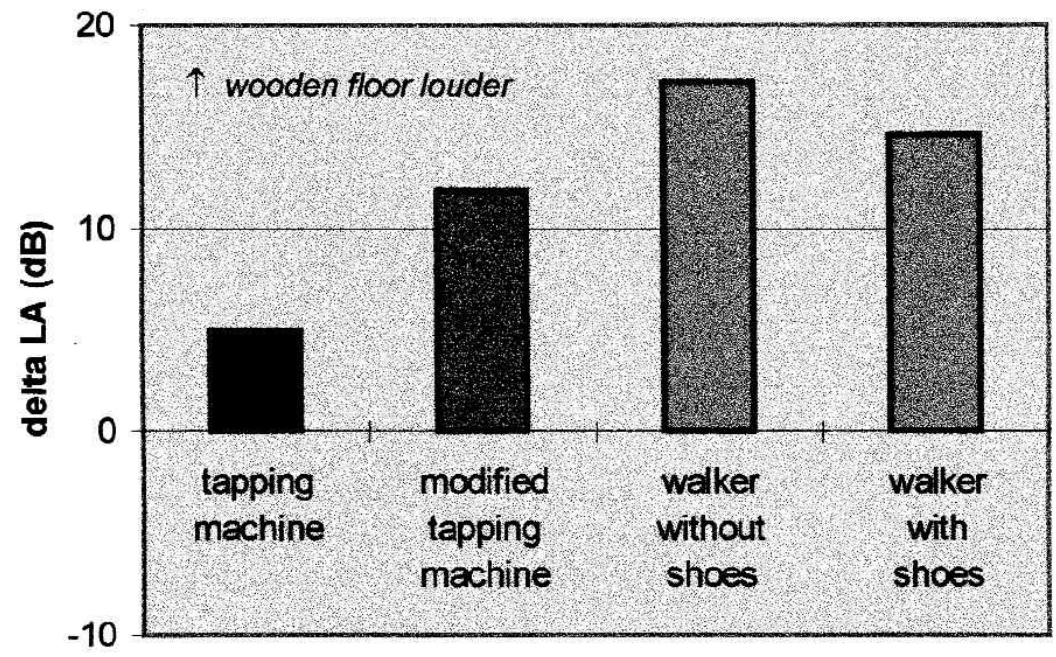

Figure 10 Difference of the A weighted impact sound pressure level for the wooden and concrete floors, using the modified and standard tapping machines, and a walker with and without shoes 
walker produced 16 to $18 \mathrm{~dB}$ higher levels on the wooden floor, and the modified tapping machine $12 \mathrm{~dB}$, compared to those on the concrete floor. The standard tapping machine gave an opposite answer, $8 \mathrm{~dB}$ lower levels on the wooden floor compared to the concrete floor. That is at least $24 \mathrm{~dB}$ in the wrong direction.

The situation became somewhat better with the results expressed as A weighted levels. The walker revealed levels for the timber joist floor to be 15 to $17 \mathrm{~dB}$ louder, and the modified tapping machine $12 \mathrm{~dB}$ louder, compared to those for the concrete floor. The standard tapping now gives levels $5 \mathrm{~dB}$ higher for the timber joist floor, compared to the concrete floor. This is now in the right direction, at least.

It should be noted, that the A weighted level for the standard tapping machine results was calculated differently from normal A-weighting, that is by adding the normalised impact sound pressure level and the impact spectrum adaptation term $\mathrm{C}_{\mathrm{I}, 50-2500}$ according to ISO 717-2 [4]:

$$
L_{A}=L_{n, w}+C_{I, 50-2500}
$$

(This is based on a kind of spontaneous A-weighting by the standard tapping machine with respect to walking noise on some floors.)

\section{DISCUSSION OF THE RESULTS}

The above example is based on only one walking person and two floor constructions with hard surfaces. There are uncertainties concerning the influences of the static load on the source impedance of the walker. Simply because of lack of resources the measured spectrum of the walker's impedance was only simulated roughly using an existing elastic material. Nevertheless, the results for the modified tapping machine are very promising. Impact sound level spectra and single number values are much closer to those for the the walker than those with the standard tapping machine.

One of the great advantages of simulating the source impedance of the walker is that the modified tapping machine will behave on all different structures like the walker. If an adjustment of the impact sound pressure level of the modified tapping machine to the walking noise is made once, this remains valid on all floors as long as the systems tested are linear. For sources with different impedance there is no such a correction. It is not possible to show this by comparing the test results from only two floors. Future research on other types of floors is therefore necessary, such as softly covered floors.

\section{FREQUENTLY ASKED QUESTIONS (FAQS)}

When discussing the matter with colleagues, several questions were repeatedly asked, which are answered in the following:

Will the reference curve for the single number rating in ISO 717-2 have to be changed when modifying the tapping machine? No, if the reference curve is intended to represent only the perception of noise. Yes, if the reference curve is to include adjustments of the modified tapping machine to walking noise. Yes, if the required performance of impact sound insulation is to be expressed by the same figures after 
replacing the standard by the modified tapping machine. This can be achieved exactly for one chosen reference floor construction, when the existing reference curve is corrected for the difference of impact sound pressure levels caused by the two different tapping machines.

Are nonlinearities taken into account with the modified tapping machine? Not completely. The modification mainly tackles the problem of impedance matching of source and receiving structure. However, some artificial nonlinear effects of the contact area of the spherically shaped hammers and the floor, are reduced by the soft interlayer of the modified machine. Including the static load of a walker could mean using hammers much heavier than $500 \mathrm{~g}$.

Is the input high enough with the modification? Suppose that the practical case of interest was not a bare concrete floor but a floor with a resilient covering. The additional softness introduced by the modification to the tapping machine might be expected to be small, so that the impact of the modified tapping machine would be similar to that of the standard tapping machine. For floating floors with hard surfaces, this should be tested.

\section{CONCLUSIONS}

Measurements of the foot input impedance of human beings, and theoretical considerations, show that the source impedance of a walker can be simulated by the standard tapping machine according to ISO 140-6 with only minor modifications, comprising an additional soft layer and a small mass of a few grams, positioned below the hammers. Such a modified tapping machine would act like a walker on any floor, be it soft or light-weight. That means that old tapping machines can continue to be used in the future. The modification can be implemented supplementary. Compared with other walker simulating devices, like dropping rubber balls, a continuous easy to measure signal is received (It should nevertheless not be forgotten that it is a line spectrum with $10 \mathrm{~Hz}$ distance between the excited frequencies!). The good agreement between results for a walker and the modified tapping machine, in contrast to those for the standard tapping machine, on two different floors, indicated that proceeding with the modified machine is recommended.

The modified tapping machine will be included as an alternative exciting device in the new standard ISO 140-11 [5], which is concerned with laboratory measurement of the impact sound improvement of floor coverings on lightweight floors. So, under well defined rules, experience with the 'new hammers' can be collected, before it is adopted as a new walking standard source. Other floors should be investigated, such as soft and floating floors, to prove the advantages of impedance simulation.

\section{ACKNOWLEDGEMENTS}

This work was carried out at the Fraunhofer-Institut für Bauphysik Stuttgart (Director: Prof. Dr. Dr. h.c. mult. Dr. E.h. mult Karl Gertis) and financially supported by the German Minister für Raumordnung, Bauwesen und Städtebau. 


\section{REFERENCES}

[1] Scholl, W. and Maysenhölder, W., Impact Sound Insulation of Timber Floors: Interaction between Source, Floor Coverings and Load Bearing Floor, Building Acoustics, Volume 6, Number 1, 1999

[2] ISO 140-6:1998, Acoustics - Measurement of sound insulation in buildings and of building elements - Part 6: Laboratory measurement of impact sound insulation of floors

[3] Gerretsen, E., A New System for Rating Impact Sound Insulation, Applied Acoustics (9), 1976, pp. 247-263

[3] ISO 717-2:1996, Acoustics - Rating of sound insulation in buildings and of building elements - Part 2: Impact sound insulation

[4] ISO/CD 140-11:2000, Acoustics - Measurement of sound insulation in buildings and of building elements - Part 11: Laboratory measurement of the reduction of transmitted impact noise by floor coverings on light-weight framed standard floors 